\title{
Corrosion Inhibition Effect of N-(4-diethylaminobenzyl) Quaternary Ammonium Chitosan for X80 Pipeline Steel in Hydrochloric Acid Solution
}

\author{
Ping Li, Liang He ${ }^{*}$ Xinqi Li, Xinran Liu, Min Sun \\ School of Materials Engineering, Shanghai University of Engineering Science, Shanghai 201620, \\ China \\ *E-mail: jlljhl@163.com
}

doi: $10.20964 / 2021.01 .07$

Received: 4 Sepember 2020 / Accepted: 26 October 2020 / Published: 30 November 2020

\begin{abstract}
Two water-soluble chitosan derivatives of quaternary amine salt chitosan and N-(4-diethylaminobenzyl) quaternary ammonium chitosan were synthesised, characterised and deployed as corrosion inhibitors for X80 pipeline steel in $1 \mathrm{M}$ hydrochloric acid solution. DAC exhibits better corrosion inhibition performance due to more adsorption centres and more stable adsorption. The potentiodynamic polarization curves revealed that the inhibitors are mixed inhibitors dominated by the anodic reaction. Electrochemical impedance spectroscopy revealed that the corrosion inhibition process is chargetransfer control. The adsorption of inhibitors obeys the Langmuir adsorption isotherm. The thermodynamic parameters of adsorption and surface analysis (SEM, X-ray photoelectron spectroscopy and contact angle) are also discussed.
\end{abstract}

Keywords: chitosan derivative; corrosion inhibitor; electrochemical; surface analysis; X80 pipeline steel

\section{$\underline{\text { FULL TEXT }}$}

(C) 2021 The Authors. Published by ESG (www.electrochemsci.org). This article is an open access article distributed under the terms and conditions of the Creative Commons Attribution license (http://creativecommons.org/licenses/by/4.0/). 